\title{
Bioconcentração de chumbo e micronutrientes em hortaliças cultivadas em solo contaminado ${ }^{1}$
}

\author{
Bioconcentration of lead and micronutrients in horticultural crops grown in \\ contaminated soil
}

\author{
Francisco de Sousa Lima ${ }^{2 *}$, Clístenes Williams Araújo do Nascimento ${ }^{3}$, Adriana Maria de Aguiar Accioly ${ }^{4}$, Carla \\ da Silva Sousa ${ }^{5}$ e Fernando Ferreira da Cunha Filho ${ }^{6}$
}

\begin{abstract}
RESUMO - A crescente poluição ambiental nas últimas décadas vem tornando os metais pesados uma ameaça constante aos seres vivos. Entre estes, o chumbo $(\mathrm{Pb})$ é um dos mais importantes, devido à quantidade de áreas contaminadas e seus efeitos deletérios para saúde humana. Este estudo objetivou avaliar a produção de biomassa e absorção de micronutrientes por olerícolas cultivadas em Espodossolo contaminado por $\mathrm{Pb}$. Adicionalmente, a distribuição de $\mathrm{Pb}$ entre as frações do solo e a relação dessas frações com a disponibilidade do $\mathrm{Pb}$ para hortaliças foi também estudado. O experimento foi conduzido em blocos casualizados no

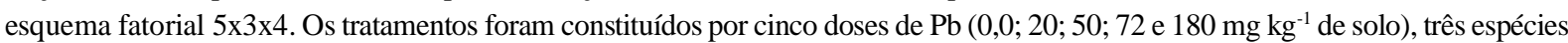
vegetais (quiabo, cenoura e couve-manteiga) e quatro partes das plantas (raiz, caule, folha e partes comestíveis), sendo a última dose equivalente ao valor de investigação para solos agrícolas. De acordo com os resultados, o Pb promoveu redução da matéria seca nas plantas de cenoura e quiabeiro, enquanto não influenciou a produção de biomassa da couve manteiga. $\mathrm{O} \mathrm{Pb}$ afetou a concentração de micronutrientes nos órgãos das hortaliças, sendo observado na cenoura redução no teor de ferro enquanto na couve manteiga houve aumento do teor de $\mathrm{Zn}$ nas raízes. $\mathrm{O} \mathrm{Pb}$ apresentou-se, preferencialmente, adsorvido à fração matéria orgânica. Plantas cultivadas em solo contaminado com a dose de investigação estabelecida pelo CONAMA, além de apresentarem desbalanço nutricional, podem tornar-se inadequadas ao consumo humano, devido ao elevado teor deste metal nas partes comestíveis.
\end{abstract}

Palavras-chave: Hortaliças. Solo-poluição. Plantas-efeito de metais pesados.

ABSTRACT - Increasing environmental pollution in recent decades has made heavy metals a constant threat to living beings. Among these, lead $(\mathrm{Pb})$ is one of the most important, because of the number of contaminated areas, and their deleterious effects on human health. This study aimed to evaluate biomass production and the absorption of micronutrients by horticultural crops grown in a spodosol contaminated by $\mathrm{Pb}$. In addition, the distribution of $\mathrm{Pb}$ among the soil fractions and the relationship of these fractions to the availability of $\mathrm{Pb}$ to the crops was also studied. The experiment was carried out in randomized blocks in a $5 \times 3 \times 4$ factorial scheme. The treatments were made up of five levels of $\mathrm{Pb}\left(0.0 ; 20 ; 50 ; 72\right.$ and $180 \mathrm{mg} \mathrm{kg}^{-1}$ of soil), three species of vegetable (okra, carrot and kale) and four plant parts (root, stem, leaf and edible portions), the last level being equivalent to the investigative value for agricultural soils. According to the results, the $\mathrm{Pb}$ promoted a reduction in the dry mass of the carrot and okra, while having no effect on the biomass production of the kale. The $\mathrm{Pb}$ affected the concentration of micronutrients in the vegetable organs, a reduction in iron content being observed in the carrot, while in the kale there was an increase in the $\mathrm{Zn}$ content of the roots. The $\mathrm{Pb}$ presented as preferably adsorbed to the organic-matter fraction. Plants grown in soil contaminated at the investigative levels established by CONAMA, besides showing nutritional imbalance, may become unsuitable for human consumption, due to the high levels of the metal in the edible portions.

Key words: Vegetables. Soil-pollution. Plants-effect heavy metal.

\footnotetext{
*Autor correspondente

'Recebido para publicação em 11/12/2010; aprovado 12/09/2012

Parte da Tese de Doutorado do primeiro autor, apresentada ao Programa de Pós-Graduação em Ciência do Solo/UFRPE

${ }^{2}$ Centro de Ciências Agrárias, Ambientais e Biológicas/UFRB, Cruz das Almas-BA, Brasil, fsousalima@ yahoo.com.br

${ }^{3}$ Departamento de Agronomia, Ciência do Solo/UFRPE, Recife-PE, Brasil, cwanascimento@yahoo.com

${ }^{4}$ Embrapa Mandioca e Fruticultura, Cruz das Almas-BA, Brasil, adriana @ cnpmf.embrapa.br

${ }^{5}$ Centro de Ciências Agrárias, Ambientais e Biológicas/UFRB, Cruz das Almas-BA, Brasil, cssagro@ yahoo.com.br

${ }^{6}$ Universidade Federal Rural de Pernambuco, Recife-PE, Brasil, fernandofcfilho@ hotmail.com
} 


\section{INTRODUÇÃO}

Metais pesados estão presentes nos solos como componentes naturais ou como resultado das atividades antropogênicas. O repetido uso de insumos como fertilizantes, corretivos e lodo de esgoto em atividades agrícolas, tem, em alguns casos, elevado o teor de metais pesados no solo (LI et al., 2007). O crescimento urbano e industrial também tem causado contaminação ambiental e dentre as atividades que mais contribuem para a poluição do solo estão a indústria metalúrgica e a mineração (GUPTA; SINHA, 2006).

$\mathrm{O} \mathrm{Pb}$ tem destaque entre os metais pesados devido à sua ampla utilização e persistência no solo, sendo considerado um dos poluentes mais importantes. Este elemento, quando incorporado ao solo, pode afetar a cadeia alimentar, constituindo importante ameaça em virtude de sua alta toxicidade para seres humanos (TORRI; LAVADO, 2009).

As plantas restringem o transporte de $\mathrm{Pb}$ para a parte aérea, acumulando-o preferencialmente nas raízes, devido a proteção efetuada pela endoderme (VERMA; DUBEY, 2003). Esta retenção de $\mathrm{Pb}$ na raiz pode, também, ser atribuída à ligação do elemento às cargas negativas da parede celular presentes neste órgão da planta (LIU et al., 2009). Embora o vegetal restrinja o transporte do $\mathrm{Pb}$ a longa distância, o elemento acumula-se nas diversas partes das plantas e sua fitotoxicidade pode afetar a atividade de enzimas e promover alterações hormonais (TEKLIC et al., 2008). O Pb também pode proporcionar inibição da fotossíntese, alterações na estrutura e permeabilidade da membrana celular e distúrbios na nutrição mineral das plantas (SARMA; HENDIQUE; HENDIQUE, 2006).

É pertinente ressaltar, contudo, que o elevado teor de $\mathrm{Pb}$ no solo não reflete o potencial de transferência desse elemento para a cadeia alimentar, tendo em vista sua forte capacidade adsortiva, principalmente a óxidos de Fe e argilominerias, o que ocasiona baixa mobilidade no solo (BOSSO; ENZWEILER, 2008). O teor total de Pb tem sido usado para avaliar o seu efeito na contaminação do solo (CHEN et al., 2009). Entretanto, o teor total não indica os compartimentos do solo em que o elemento se encontra nem a biodisponibilidade para organismos vivos (LI et al., 2007), pois, dependendo da fração do solo, o $\mathrm{Pb}$ pode estar fortemente retido e não disponível em curto prazo (BOSSO; ENZWEILER, 2008).

$\mathrm{O}$ potencial biodisponível de $\mathrm{Pb}$ no solo tem sido avaliado através de extratores químicos, tais com EDTA e DTPA, ou através de fracionamento do solo (LI et al., 2007). No entanto, o fracionamento é uma técnica de extração seletiva que define a proporção do metal associada a cada componente da fase sólida do solo e tem sido amplamente utilizada para avaliar a mobilidade de metais pesados (GUEVARA-RIBA et al., 2004). O fracionamento permite predizer o potencial do metal biodisponível, bem como o potencial de mobilidade, lixiviação e poluição dos solos (ISHIKAWA et al., 2009). Nesta técnica, o solo é submetido a uma série de reagentes químicos de reatividade crescente, sendo que a fitodisponibilidade do $\mathrm{Pb}$ apresenta-se em ordem decrescente com relação às etapas da extração sequencial (TORRI; LAVADO, 2009). $\mathrm{O}$ teor de $\mathrm{Pb}$ disponível e adsorvido na forma trocável no solo indica alta mobilidade e biodisponibilidade imediata, enquanto as concentrações presentes nas frações matéria orgânica, óxidos de Mn e Fe amorfo e cristalino indicam que o metal está imobilizado, com menor risco de contaminação ambiental (LU; ZHANG; SHAN, 2005).

Neste contexto, o objetivo deste estudo foi: 1) avaliar o efeito do $\mathrm{Pb}$ sobre a produção de biomassa e a absorção de micronutrientes pelas plantas, 2) verificar se o teor de $\mathrm{Pb}$ no solo equivalente ao valor de investigação determinado pelo CONSELHO NACIONAL DO MEIO AMBIENTE (2009) para solos agrícolas é protetivo à saúde humana quanto ao teor de $\mathrm{Pb}$ em partes comestíveis; e, 3) avaliar a distribuição do $\mathrm{Pb}$ entre as frações de um Espodossolo, bem como a relação dessas frações com a disponibilidade do elemento para hortaliças.

\section{MATERIAL E MÉTODOS}

O experimento foi desenvolvido em casa de vegetação, no período de janeiro a abril de 2009. Amostra de um Espodossolo Distrófico, textura arenosa, foi coletada na profundidade de 0 a $20 \mathrm{~cm}$ e, em seguida, seco ao ar, destorroado, homogeneizado e peneirado em malha de $2 \mathrm{~mm}$. As análises químicas e físicas foram realizadas conforme (EMPRESA BRASILEIRA DE PESQUISA AGROPECUÁRIA, 1997, 1999), exceto o $\mathrm{Pb}$ que foi determinado pelo USEPA $3050 \mathrm{~B}$ (UNITED STATES ENVIRONMENTAL PROTECTION AGENCY, 1998), conforme Tabela 1. O solo foi incubado por 20 dias com carbonato de cálcio e dióxido de magnésio (3:1), visando elevar o $\mathrm{pH}$ para 6,5. Posteriormente, promoveu-se a incubação durante 30 dias com $\mathrm{Pb}\left(\mathrm{NO}_{3}\right)_{2}$, com concentrações ajustadas para 0,$0 ; 20,0 ; 50,0 ; 72,0$ e 180,0 mg de $\mathrm{Pb}$ por $\mathrm{kg}$, sendo este último valor o nível de investigação indicado pela legislação brasileira para solos agrícolas (CONSELHO NACIONAL DO MEIO AMBIENTE, 2009). Após a incubação, 6,0 kg de solo foram acondicionados em vasos plásticos, constituindo as unidades experimentais. Em cada vaso plástico, coletou-se amostra de solo para determinar o $\mathrm{Pb}$ disponível por EDTA e DTPA (LANTMANN; MEURER, 1982; LINDSAY; NORVELL, 1978) e o fracionamento do metal nos compartimentos do solo, foi efetuado pelo método de Shuman (1985), com exceção da fração óxido de ferro amorfo que foi caracterizada conforme Chao e Zhou (1983). 
Tabela 1 - Características químicas e físicas do Espodossolo Distrófico, textura arenosa, utilizado no experimento

\begin{tabular}{lc}
\hline \multicolumn{1}{c}{ Característica } & Valor \\
\hline $\mathrm{pH}\left(\mathrm{água}^{-1: 2,5)}\right.$ & 5,1 \\
$\mathrm{P}\left(\mathrm{mg} \mathrm{dm}^{-3}\right)$ & 8,30 \\
$\mathrm{Na}^{+}\left(\mathrm{cmol}_{\mathrm{c}} \mathrm{dm}^{-3}\right)$ & 0,31 \\
$\mathrm{~K}^{+}\left(\mathrm{cmol}_{\mathrm{c}} \mathrm{dm}^{-3}\right)$ & 0,10 \\
$\mathrm{Ca}^{+2}\left(\mathrm{cmol}_{\mathrm{c}} \mathrm{dm}^{-3}\right)$ & 4,40 \\
$\mathrm{Mg}^{+2}\left(\mathrm{cmol}_{\mathrm{c}} \mathrm{dm}^{-3}\right)$ & 2,90 \\
$\mathrm{Al}{ }^{+3}\left(\mathrm{cmol}_{\mathrm{c}} \mathrm{dm}^{-3}\right)$ & 0,15 \\
$\mathrm{H}+\mathrm{Al}\left(\mathrm{cmol}_{\mathrm{c}} \mathrm{dm}^{-3}\right)$ & 2,80 \\
$\mathrm{~Pb}\left(\mathrm{mg} \mathrm{kg}^{-1}\right)$ & 16,50 \\
$\mathrm{C} . \mathrm{O}\left(\mathrm{g} \mathrm{kg}^{-1}\right)$ & 15,63 \\
$\mathrm{M} . \mathrm{O}\left(\mathrm{g} \mathrm{kg}^{-1}\right)$ & 27,0 \\
Areia $\left(\mathrm{g} \mathrm{kg}^{-1}\right)$ & 940,0 \\
Silte $\left(\mathrm{g} \mathrm{kg}^{-1}\right)$ & 27,0 \\
Argila $\left(\mathrm{g} \mathrm{kg}^{-1}\right)$ & 33,0 \\
\hline
\end{tabular}

Para instalação do experimento, as mudas de cenoura (Daucos carota), couve manteiga (Brassica oleracea var. acephala) e quiabo (Abelmoschus esculentus), previamente produzidas em bandejas de isopor, foram transplantadas para vasos com solo previamente adubado (NASCIMENTO; AMANASINIWANDENA; XING, 2006), sendo utilizadas 04 mudas/vaso. Estas espécies foram escolhidas por representarem diferentes partes comestíveis (tubéra, folha e fruto). Durante o experimento, a umidade do solo foi mantida a $80 \%$ da capacidade máxima de retenção de água. Ao final do ciclo, raízes e parte aérea foram coletadas separadamente, lavadas em água de torneira e em seguida em água destilada. Após lavadas, parte aérea e radicular foram, individualmente, acondicionadas em sacos de papel devidamente identificadas e colocadas em estufa com ventilação forçada, à temperatura entre 65$70{ }^{\circ} \mathrm{C}$, por três dias. As amostras secas foram pesadas e trituradas em moinho tipo Wiley e em seguida submetidas à digestão nitroperclórica (EMPRESA BRASILEIRA DE PESQUISAAGROPECUÁRIA, 1999), sendo os teores de $\mathrm{Pb}, \mathrm{Fe}, \mathrm{Zn}, \mathrm{Mn}$ e Ni quantificados por ICP-OES (Perkin Elmer Optima 7000 DV).

O experimento foi desenvolvido em delineamento experimental de blocos casualizados em esquema fatorial $5 \times 3 \times 4$. Os tratamentos consistiram de cinco doses de $\mathrm{Pb}$ $\left(0,0 ; 20,0 ; 50,0 ; 72,0\right.$ e $180,0 \mathrm{mg} \mathrm{kg}^{-1} \mathrm{de}$ solo), três espécies de olerícolas (cenoura, couve manteiga e quiabo) e quatro partes da planta (raiz, caule, folha e parte comestível), com quatro repetições. Os dados obtidos foram submetidos à análise de variância e os testes de comparações de média, análise de regressão e correlação foram realizados por meio do SAS (2000), ao nível de 0,05 de probabilidade.

\section{RESULTADOS E DISCUSSÃO}

Conforme resumo da análise de variância, verificouse interação tripla significativa no fatorial composto por cinco doses de $\mathrm{Pb}$, três espécies de hortaliças e quatro partes destas culturas $(5 \times 3 \times 4)$ (Tabela 2). Neste sentido, o desdobramento

Tabela 2 - Resumo da análise de variância geral (quadrados médios) para as variáveis estudadas nas hortaliças, em função das doses de $\mathrm{Pb}$ aplicadas ao solo

\begin{tabular}{|c|c|c|c|c|c|c|}
\hline \multirow{2}{*}{ FV } & \multirow{2}{*}{ GL } & \multicolumn{5}{|c|}{ Quadrado médio } \\
\hline & & $\mathrm{Pb}$ & $\mathrm{Fe}$ & $\mathrm{Mn}$ & $\mathrm{Ni}$ & $\mathrm{Zn}$ \\
\hline Bloco & 3 & $1,21 \times 102^{\mathrm{ns}}$ & $5,91 \times 102^{\mathrm{ns}}$ & $5,75 \times 103 *$ & $0,40 \times 10^{*}$ & $16,08 \times 102 *$ \\
\hline Cultura (C) & 2 & $32,90 \times 103 * * *$ & $5,61 \times 104 * *$ & $28,06 \times 104 * * *$ & $24,34 \times 102 * * *$ & $28,95 \times 103 * * *$ \\
\hline Dose (D) & 4 & $67,53 \times 103 * * *$ & $5,53 \times 103 * * *$ & $71,48 \times 103 * * *$ & $1,42 \times 10 * *$ & $76,67 \times 102 * *$ \\
\hline Parte (P) & 3 & $12,97 \times 104 * * *$ & $6,88 \times 104 * * *$ & $10,66 \times 105^{* * *}$ & $12,77 \times 103 * *$ & $68,06 \times 102 * *$ \\
\hline $\mathrm{C} \times \mathrm{D}$ & 8 & $99,85 \times 102 * * *$ & $16,33 \times 103 * *$ & $7,41 \times 103 * *$ & $2,58 \times 10 * * *$ & $12,75 \times 102 * * *$ \\
\hline $\mathrm{C} \times \mathrm{P}$ & 6 & $35,61 \times 103 * * *$ & $20,08 \times 104 * * *$ & $62,09 \times 104 * * *$ & $11,01 \times 103 * *$ & $49,79 \times 103 * * *$ \\
\hline $\mathrm{D} \times \mathrm{P}$ & 12 & $40,91 \times 103 * *$ & $11,47 \times 103^{* *}$ & $54,84 \times 103 * *$ & $2,66 \times 10^{* * *}$ & $14,37 \times 102 * * *$ \\
\hline $\mathrm{C} \times \mathrm{D} \times \mathrm{P}$ & 24 & $10,07 \times 103 * * *$ & $94,38 \times 102 * * *$ & $14,72 \times 103 * * *$ & $4,06 \times 10 * * *$ & $6,88 \times 102 * * *$ \\
\hline Erro & 177 & 123.81 & 435,50 & $2.524,49$ & 1,69 & 200,97 \\
\hline Média geral & - & 40,19 & 137,98 & 206,46 & 32,57 & 81,63 \\
\hline $\mathrm{CV}(\%)$ & - & 27,68 & 15,12 & 24,34 & 4,00 & 17,36 \\
\hline
\end{tabular}

*** $\mathrm{e}^{* * *}$ significativos a 5,1 e $0,1 \%$, respectivamente; $\mathrm{ns}=$ não significativo 
dos graus de liberdade da interação entre culturas, doses de $\mathrm{Pb}$ aplicadas ao solo e partes destes vegetais, foi utilizado para estudo do efeito das doses de $\mathrm{Pb}$, na produção de biomassa seca das plantas, nos teores de $\mathrm{Pb}, \mathrm{Fe}, \mathrm{Mn}, \mathrm{Ni}$ e Zn observados nas culturas, bem como nas partes destes vegetais.

$\mathrm{O} \mathrm{Pb}$ promoveu redução significativa na produção de matéria seca das raízes e partes comestíveis da cenoura (Figura 1). A redução da matéria seca pode ser atribuída à redução da respiração, alterações na fotossíntese e no metabolismo do nitrogênio causados pelo excesso de $\mathrm{Pb}$ na planta (MERWE et al., 2009).

Figura 1 - Produção de matéria seca $\left(\mathrm{g} \mathrm{vaso}^{-1}\right)$ nas partes de cenoura, couve manteiga e quiabo, em resposta às doses crescentes de $\mathrm{Pb}$ aplicado no solo

\section{CENOURA}
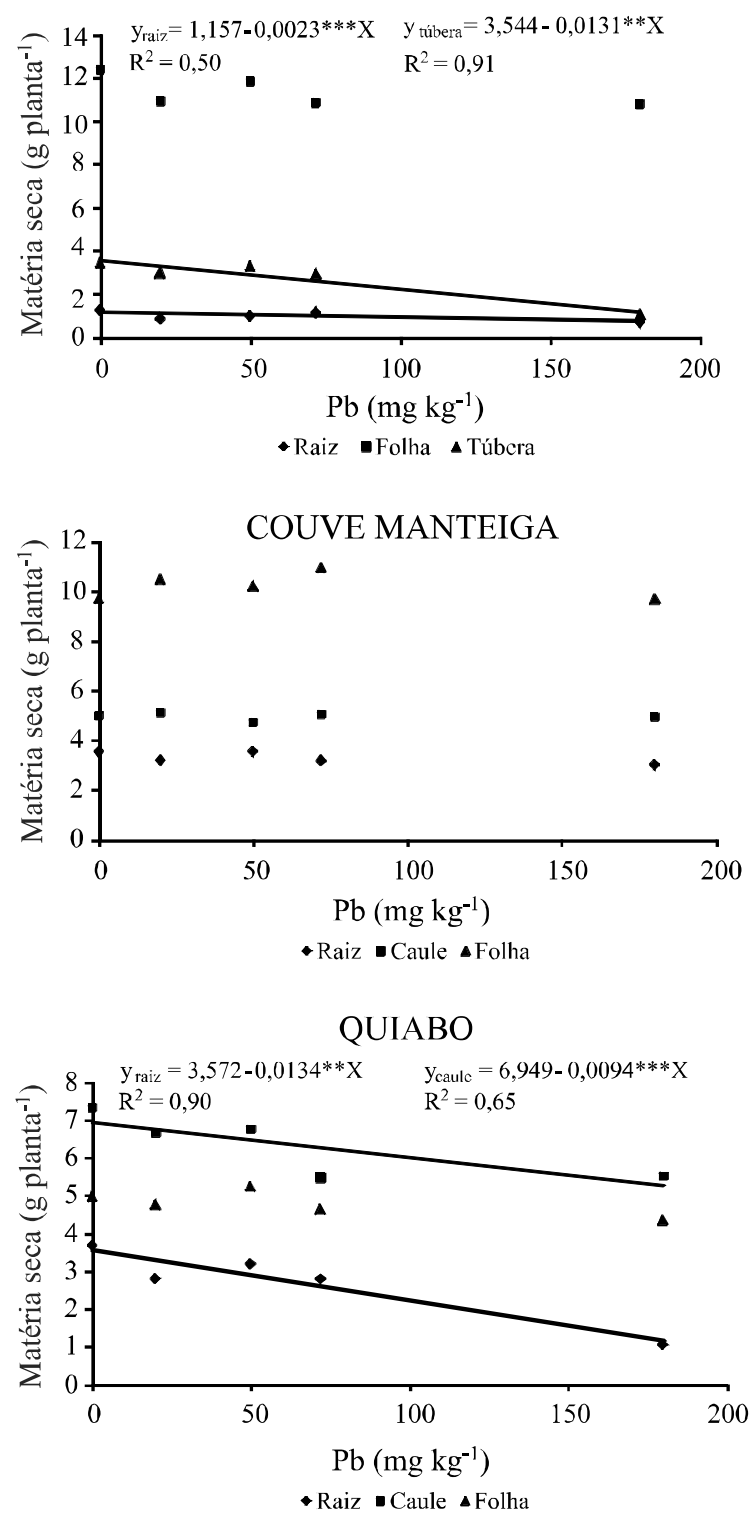

No quiabeiro, a produção de matéria seca das raízes e caule foi afetada, enquanto na couve manteiga não houve efeito negativo do $\mathrm{Pb}$ na produção de biomassa em nenhum dos órgãos da planta. Isto demonstra que a couve manteiga é menos sensível aos efeitos adversos do $\mathrm{Pb}$, o que corrobora a informação que este metal afeta os vegetais de forma diferenciada (HUSSAIN; LJAZ; BIBI, 2006). Estes resultados demonstraram ainda que, embora $\mathrm{o} \mathrm{Pb}$ seja um metal fitotóxico, algumas espécies vegetais se desenvolvem em solos contaminados por este elemento sem apresentar redução no rendimento da matéria seca (HONG et al., 2008). O reduzido efeito da fitotoxidez do $\mathrm{Pb}$ pode ainda ser atribuído ao baixo teor disponível do metal, tendo em vista sua forte capacidade adsortiva com os componentes do solo (BOSSO; ENZWEILER, 2008). Portanto, alto teor de $\mathrm{Pb}$ no solo não está, necessariamente, relacionado com elevada toxidez aos vegetais.

Houve aumento significativo da concentração do $\mathrm{Pb}$ nas raízes das plantas avaliadas (Tabela 3), corroborando os resultados de Sinha et al. (2006) em plantas de repolho cultivadas sob altas doses de chumbo. A retenção de $\mathrm{Pb}$ nas raízes ocorre devido à formação de precipitados de carbonato de $\mathrm{Pb}$ ou através da ligação do elemento às cargas negativas presentes na parede celular (SHARMA; DUBEY, 2005). Além disto, o aumento do teor de $\mathrm{Pb}$ nas raízes de cenoura e quiabeiro pode ser atribuído à menor produção de matéria seca neste órgão, devido às elevadas doses do metal aplicadas no solo cultivado (Figura 1).

$\mathrm{O}$ aumento do teor de $\mathrm{Pb}$ nas partes comestíveis da cenoura e da couve manteiga, decorrente da aplicação de doses crescentes de $\mathrm{Pb}$ no solo, indica que esses vegetais podem absorver e concentrar elevados teores

Tabela 3 - Equações de regressão para os teores de $\mathrm{Pb}$ nas partes das plantas de cenoura, couve manteiga e quiabo $(\mathrm{Y})$ em resposta às doses crescentes do metal aplicadas no solo $(\mathrm{X})$

\begin{tabular}{llc}
\hline Parte da planta & \multicolumn{1}{c}{ Equação de regressão } & $\mathrm{R}^{2}$ \\
\hline Raiz & $\mathrm{Y}=0,159+3,377 * * * \mathrm{X}$ & 0,99 \\
Folha & $\mathrm{Y}=7,593$ & - \\
Túbera & $\mathrm{Y}=13,552+0,285 * * \mathrm{X}$ & 0,84 \\
\hline \multicolumn{3}{c}{ Couve manteiga } \\
\hline Raiz & $\mathrm{Y}=0,571+0,925 * * * \mathrm{X}$ \\
Caule & $\mathrm{Y}=9,823+0,117 * * \mathrm{X}$ \\
Folha & $\mathrm{Y}=10,518+0,070 * \mathrm{X}$ \\
\hline \multicolumn{3}{c}{$\mathrm{Quiabo}$} \\
\hline Raiz & $\mathrm{Y}=9,122+1,014 * * * \mathrm{X}$ & 0,62 \\
Caule & $\mathrm{Y}=13,006+0,358 * * * \mathrm{X}$ \\
Folha & $\mathrm{Y}=5,506+0,412 * \mathrm{X}-0,002 * \mathrm{X}^{2}$ & 0,68 \\
\hline$* * *$ e $* *$ significativos a $5,1, \mathrm{e} 0,1 \%$ respectivamente \\
\end{tabular}


deste metal nestes órgãos. Contudo, com relação à parte comestível da cenoura, este aumento na concentração de $\mathrm{Pb}$ pode ser atribuído à menor produção de biomassa neste órgão quando as plantas foram cultivadas no solo com $180 \mathrm{mg}$ de $\mathrm{Pb}$ por kg de solo (Figura 1).

Constatou-se ainda que, quando as plantas foram cultivadas no solo contaminado com $180 \mathrm{mg} \mathrm{kg}^{-1}$, os teores deste metal na parte comestível da cenoura e couve manteiga (5,18 e $1,28 \mathrm{mg} \mathrm{kg}^{-1}$ de peso fresco, respectivamente), superaram os limites considerados toleráveis pelo (CODEX ALIMENTARIUS, 2009). Este nível de contaminação é considerado o limite de investigação para áreas agrícolas pelo CONSELHO NACIONAL DO MEIO AMBIENTE (2009) e, neste sentido, o solo não deve ser cultivado para a produção de alimentos, tendo em vista que $\mathrm{o} \mathrm{Pb}$ poderá ser transferido às partes comestíveis dos vegetais, constituindo risco à população.

$\mathrm{Nas}$ folhas de quiabeiro, o teor de $\mathrm{Pb}$ apresentou comportamento quadrático, de modo que a partir da dose $103 \mathrm{mg}$ de $\mathrm{Pb}$ por kg-1 de solo, o metal possivelmente promoveu efeito fitotóxico e a planta restringiu o seu transporte para este órgão, ficando possivelmente retido pelas cargas negativas presentes nas paredes das células da raiz (LIU et al., 2009).

$\mathrm{A}$ adição de $\mathrm{Pb}$ afetou significativamente a concentração de micronutrientes nos órgãos das hortaliças. Nas raízes da cenoura, observou-se redução no teor de $\mathrm{Fe}$, enquanto as concentrações de $\mathrm{Ni}$ e $\mathrm{Zn}$ apresentam comportamento quadrático (Tabela 4). Nas folhas, verificou-se que os teores de Fe, Mn e Zn reduziram de forma linear, embora o teor de $\mathrm{Ni}$ não tenha sido afetado pelo $\mathrm{Pb}$ adicionado ao solo. Redução nos teores de $\mathrm{Fe}$ e Mn decorrente de doses crescentes de Pb também foi observada nas raízes e folhas de repolho (SINHA et al., 2006), possivelmente devido à inibição competitiva, bloqueando a entrada destes elementos na planta (SHARMA; DUBEY, 2005). O Pb proporcionou aumento linear significativo nas concentrações de $\mathrm{Ni}$ e $\mathrm{Zn}$ nas túberas de cenoura. No entanto, o teor de Fe apresentou comportamento quadrático, enquanto a concentração de $\mathrm{Mn}$ não foi significativamente afetada pelo chumbo. $\mathrm{O} \mathrm{Pb}$ pode alterar a seletividade da membrana plasmática nas células das raízes, afetando a absorção, o transporte e a alocação dos nutrientes nas partes das plantas, resultando no desbalanço nutricional (SHARMA; DUBEY, 2005).

$\mathrm{Na}$ couve manteiga, o $\mathrm{Pb}$ promoveu redução das concentrações de $\mathrm{Fe}, \mathrm{Mn}$ e Ni nas folhas, embora tenha proporcionado aumento do teor de $\mathrm{Zn}$ neste órgão. Os teores de $\mathrm{Ni}$ e $\mathrm{Zn}$ na raiz não foram afetados pela adição de $\mathrm{Pb}$, contudo, verificou-se aumento na concentração de $\mathrm{Fe}$, corroborando os resultados de Gopal e Rizvi (2008) que também constataram aumento na concentração de Fe nas raízes das plantas de rabanete cultivadas com doses de chumbo. Nas raízes de quiabeiro, o $\mathrm{Pb}$ promoveu redução do teor de $\mathrm{Fe}$, não afetou a concentração de $\mathrm{Mn}$, enquanto que os teores de $\mathrm{Ni}$ e $\mathrm{Zn}$ apresentaram comportamento quadrático. A redução do $\mathrm{Fe}$ nas raízes das plantas do quiabeiro pode ser devido ao bloqueio promovido pelo $\mathrm{Pb}$ limitando a entrada de cátions no sistema radicular das plantas (SHARMA; DUBEY, 2005). No caule, observouse que o $\mathrm{Pb}$ reduziu o teor de $\mathrm{Zn}$, entretanto não alterou as concentrações dos demais micronutrientes. $\mathrm{O}$ teor de $\mathrm{Ni}$ nas folhas de quiabeiro não foi afetado pelo $\mathrm{Pb}$, embora tenha sido observada redução das concentrações de $\mathrm{Fe}$, Mn e Zn neste órgão da planta.

Estes resultados observados nas três espécies avaliadas, em relação ao teor dos elementos constatados nos órgãos das plantas, indicam que houve um desbalanço nutricional nestas plantas, o que segundo Paivoke (2002) pode ser considerado um dos principais impactos do excesso de $\mathrm{Pb}$ sobre os vegetais.

As concentrações de $\mathrm{Pb}$ disponível, determinadas através dos extratores EDTA e DTPA, apresentaram correlação positiva e significativa com os teores do elemento na fração trocável e matéria orgânica (Tabela 5), indicando que o teor do metal determinado nestas frações do solo, também apresenta-se potencialmente disponível às plantas (LI et al., 2007).

Os maiores coeficientes de correlação observados entre os teores de $\mathrm{Pb}$ nas partes da planta e na fração trocável do solo, comparativamente à matéria orgânica, sugerem que o teor de $\mathrm{Pb}$ determinado naquela fração, por estar adsorvido mais fracamente, é um bom indicativo do metal potencialmente disponível às plantas (LI et al., 2007).

$\mathrm{O} \mathrm{Pb}$ retido nas frações óxido de ferro amorfo e cristalino, apresentou menores coeficientes de correlação com o teor de $\mathrm{Pb}$ nos órgãos das plantas, comparativamente às demais frações avaliadas, demonstrando que o metal adsorvido nestas frações do solo não está potencialmente disponível aos vegetais. A forte retenção do $\mathrm{Pb}$ nos óxidos de ferro, decorrente das intensas ligações químicas, faz com que este metal apresente-se pouco móvel no ambiente e, consequentemente, pouco disponível às plantas (BOSSO; ENZWEILER, 2008).

A distribuição do $\mathrm{Pb}$, representado pelo teor natural do solo mais a dose aplicada, apresentou variações significativas, sendo os menores teores observados na fração residual (Tabela 6). Observou-se ainda predominância do $\mathrm{Pb}$ ligado à matéria orgânica, seguido da fração óxido de ferro cristalino. A adição do $\mathrm{Pb}$ ao solo não aumentou a concentração do elemento na fração trocável, possivelmente em decorrência do baixo teor de argila (Tabela 1) e devido ao $\mathrm{pH}$ do solo que foi corrigido para 6,5 favorecendo aos processos de complexação, precipitação e quimiossorção por óxidos e filossilicatos. A predominância do $\mathrm{Pb}$ adsorvido à fração matéria orgânica, pode estar associada à percentagem relativa desta fração no solo (Tabela 1) ou decorre, ainda, da afinidade do metal por esta fração do solo (LINHARES et al., 2009). Esta distribuição de $\mathrm{Pb}$ corrobora os resultados observados por outros autores (COSTA et al., 2007) ao promoverem o fracionamento seqüencial do $\mathrm{Pb}$ em solos. 
Tabela 4 - Equações de regressão para os teores de micronutrientes nas partes das plantas de cenoura, couve manteiga e quiabo em resposta às doses crescentes de $\mathrm{Pb}$ aplicado no solo

\begin{tabular}{|c|c|c|c|}
\hline Nutriente & Parte da planta & Equação de regressão & $\mathrm{R}^{2}$ \\
\hline \multicolumn{4}{|c|}{ Cenoura } \\
\hline \multirow{3}{*}{$\mathrm{Fe}$} & Raiz & $Y=165,889-0,1816 * X$ & 0,77 \\
\hline & Folha & $\mathrm{Y}=183,901-0,343^{* * *} \mathrm{X}$ & 0,73 \\
\hline & Túbera & $\mathrm{Y}=123,985+6,193 * * * \mathrm{X}-0,025 * * * \mathrm{X}^{2}$ & 0,86 \\
\hline \multirow{3}{*}{ Mn } & Raiz & $\mathrm{Y}=645,229$ & - \\
\hline & Folha & $\mathrm{Y}=429,979-1,354 * * * \mathrm{X}$ & 0,67 \\
\hline & Túbera & $\mathrm{Y}=126,293$ & - \\
\hline \multirow{3}{*}{$\mathrm{Ni}$} & Raiz & $\mathrm{Y}=21,076+0,171 * * * \mathrm{X}-0,008 * * * \mathrm{X}^{2}$ & 0,84 \\
\hline & Folha & $\mathrm{Y}=48,982$ & - \\
\hline & Túbera & $\mathrm{Y}=52,001+0,076^{* * *} \mathrm{X}$ & 0,61 \\
\hline \multirow{3}{*}{$\mathrm{Zn}$} & Raiz & $Y=133,219+0,898 * X-0,004 * X$ & 0,95 \\
\hline & Folha & $\mathrm{Y}=92,124-0,204 * \mathrm{X}$ & 0,64 \\
\hline & Túbera & $\mathrm{Y}=103,755+0,172 * \mathrm{X}$ & 0,59 \\
\hline \multicolumn{4}{|c|}{ Couve manteiga } \\
\hline \multirow{3}{*}{$\mathrm{Fe}$} & Raiz & $\mathrm{Y}=118,483+0,310 * * \mathrm{X}$ & 0,55 \\
\hline & Caule & $\mathrm{Y}=144,240$ & - \\
\hline & Folha & $\mathrm{Y}=207,768-0,539 * * * \mathrm{X}$ & 0,62 \\
\hline \multirow{3}{*}{ Mn } & Raiz & $\mathrm{Y}=141,605+1,187 * \mathrm{X}-0,006 * \mathrm{X}$ & 0,81 \\
\hline & Caule & $\mathrm{Y}=61,212$ & - \\
\hline & Folha & $\mathrm{Y}=248,005-0,547 * * * \mathrm{X}$ & 0,72 \\
\hline \multirow{3}{*}{$\mathrm{Ni}$} & Raiz & $\mathrm{Y}=8,183$ & - \\
\hline & Caule & $\mathrm{Y}=49,005+0,003 * \mathrm{X}-0,001 \mathrm{X}^{2}$ & 0,55 \\
\hline & Folha & $\mathrm{Y}=48,955-0,001 * \mathrm{X}$ & 0,91 \\
\hline \multirow{3}{*}{$\mathrm{Zn}$} & Raiz & $\mathrm{Y}=81,099$ & - \\
\hline & Caule & $Y=116,372$ & - \\
\hline & Folha & $\mathrm{Y}=138,223+0,358 * * * \mathrm{X}$ & 0,83 \\
\hline \multicolumn{4}{|c|}{ Quiabo } \\
\hline \multirow{3}{*}{$\mathrm{Fe}$} & Raiz & $\mathrm{Y}=182,190-0,557 * * * \mathrm{X}$ & 0,60 \\
\hline & Caule & $\mathrm{Y}=137,413$ & - \\
\hline & Folha & $\mathrm{Y}=182,012-0,440 * * * \mathrm{X}$ & 0,67 \\
\hline \multirow{3}{*}{$\mathrm{Mn}$} & Raiz & $\mathrm{Y}=120,451$ & - \\
\hline & Caule & $\mathrm{Y}=157,58$ & - \\
\hline & Folha & $Y=603,913-2,964 * * * X$ & 0,73 \\
\hline \multirow{3}{*}{$\mathrm{Ni}$} & Raiz & $\mathrm{Y}=10,814+0,242 * * * \mathrm{X}-0,001 * * * \mathrm{X}^{2}$ & 0,80 \\
\hline & Caule & $\mathrm{Y}=49,283$ & - \\
\hline & Folha & $\mathrm{Y}=48,965$ & - \\
\hline \multirow{3}{*}{$\mathrm{Zn}$} & Raiz & $\mathrm{Y}=68,544+0662 * * * \mathrm{X}-0,004 * * * \mathrm{X}^{2}$ & 0,57 \\
\hline & Caule & $\mathrm{Y}=131,568-0,172 * * * \mathrm{X}$ & 0,62 \\
\hline & Folha & $\mathrm{Y}=101,046-0,298 * * * \mathrm{X}$ & 0,65 \\
\hline
\end{tabular}

$*, * * \mathrm{e}^{* * *}$ significativos a $5,1, \mathrm{e} 0,1 \%$ respectivamente 
Tabela 5 - Coeficientes de correlação linear simples de Pearson entre os teores de $\mathrm{Pb}\left(\mathrm{mg} \mathrm{kg}^{-1}\right)$ obtidos nas frações do solo: trocável (Tr), matéria orgânica (MO), óxido de ferro amorfo (OxFeA) e óxido de ferro cristalino (OxFeC) e Pb disponível extraído por EDTA e DTPA e os teores de $\mathrm{Pb}\left(\mathrm{mg} \mathrm{kg}^{-1}\right)$ na raiz $(\mathrm{R})$, parte aérea (PA) e parte comestível (PC) das hortaliças cultivadas em solo contaminado por chumbo

\begin{tabular}{lllcccc}
\hline & $\mathrm{Tr}$ & $\mathrm{MO}$ & $\mathrm{OxFeA}$ & $\mathrm{OxFeC}$ & $\mathrm{DTPA}$ & EDTA \\
\hline EDTA & $0,69 * * *$ & $0,67 * * *$ & $\mathrm{~ns}$ & $\mathrm{~ns}$ & - & - \\
DTPA & $0,72 * * *$ & $0,73 * *$ & $\mathrm{~ns}$ & $\mathrm{~ns}$ & - & - \\
R & $0,76^{* * *}$ & $0,64 * *$ & $0,55^{* *}$ & $0,49 *$ & $0,59 * *$ & $0,48 * *$ \\
PA & $0,61 * *$ & $0,49 *$ & $0,45^{*}$ & ns & $0,57 *$ & ns \\
PC & $0,54 *$ & $0,51 * *$ & ns & ns & ns & ns \\
\hline
\end{tabular}

$* * * * * * *$ significativos a 5,1 e $0,1 \%$, respectivamente; ${ }^{\text {ns }}=$ não significativo

Tabela 6 - Teor de $\mathrm{Pb}\left(\mathrm{mg} \mathrm{kg}^{-1}\right)$ nas frações do solo trocável (Tr), matéria orgânica (MO), óxido de ferro amorfo (OxFeA), óxido de ferro cristalino $(\mathrm{OxFeC})$ e residual (Res) em função da aplicação de doses crescentes

\begin{tabular}{ccrrrr}
\hline \multirow{2}{*}{ Dose de $\mathrm{Pb}$ no solo $\left(\mathrm{mg} \mathrm{kg}^{-1}\right)$} & \multicolumn{5}{c}{ Pb nas frações do solo $\left(\mathrm{mg} \mathrm{kg}^{-1}\right)$} \\
\cline { 2 - 6 } & $\mathrm{Tr}$ & $\mathrm{MO}$ & OxFeA & OxFeC & Res \\
\hline 0 & $0,83 \mathrm{~d}$ & $6,66 \mathrm{a}$ & $2,96 \mathrm{c}$ & $5,34 \mathrm{~b}$ & $0,71 \mathrm{~d}$ \\
20 & $0,91 \mathrm{~d}$ & $18,52 \mathrm{a}$ & $4,78 \mathrm{c}$ & $11,22 \mathrm{~b}$ & $1,07 \mathrm{~d}$ \\
50 & $3,81 \mathrm{~d}$ & $35,96 \mathrm{a}$ & $9,91 \mathrm{c}$ & $14,63 \mathrm{~b}$ & $2,18 \mathrm{~d}$ \\
72 & $5,59 \mathrm{~d}$ & $53,28 \mathrm{a}$ & $10,18 \mathrm{c}$ & $16,17 \mathrm{~b}$ & $3,28 \mathrm{~d}$ \\
180 & $9,66 \mathrm{c}$ & $137,66 \mathrm{a}$ & $20,37 \mathrm{~b}$ & $23,87 \mathrm{~b}$ & $4,94 \mathrm{~d}$ \\
\hline
\end{tabular}

Médias seguidas pela mesma letra minúscula nas linhas, por dose de $\mathrm{Pb}$, não diferem significativamente entre si pelo teste de Tukey, $\mathrm{P}<0,05$ )

Embora o $\mathrm{Pb}$ tenha alta afinidade pelos óxidos de Fe (SILVA; VITTI, 2008), a reduzida porcentagem do metal associada às frações óxido de Fe amorfo e cristalino, comparativamente à matéria orgânica, pode ser decorrente do baixo teor de argila presente no solo (Tabela 1).

É pertinente ressaltar que $\mathrm{o} \mathrm{Pb}$ adsorvido à fração trocável e matéria orgânica pode ser potencialmente móvel no solo. As ligações eletrostáticas do $\mathrm{Pb}$ na fração trocável fazem com que o elemento seja facilmente biodisponível (COSTA et al., 2007; LU; ZHANG; SHAN, 2005). Embora o $\mathrm{Pb}$ adsorva-se à matéria orgânica através de complexos metálicos mais estáveis que reduzem sua disponibilidade (GUPTA; SINHA, 2006 ), o metal retido nesta fração do solo pode representar potencial risco ao ambiente, tendo em vista que quando solúvel ou decomposta, a matéria orgânica pode liberar o elemento, contaminando solo, água e plantas (TORRI; LAVADO, 2009).

\section{CONCLUSÕES}

1.O Valor de Intervenção indicado pelo CONSELHO NACIONAL DO MEIO AMBIENTE (2009) para solos agrícolas contaminados por $\mathrm{Pb}$, indica a necessidade de mitigação, pois plantas alimentícias cultivadas nestas condições podem apresentar perigo à saúde humana;
2.O $\mathrm{Pb}$ afetou a absorção e a distribuição de micronutrientes nos diversos órgãos das hortaliças, causando desbalanço nutricional;

3. Os teores de $\mathrm{Pb}$ verificados nas frações trocáveis e matéria orgânica, foram bem correlacionados com as concentrações do metal na planta e podem predizer o potencial de biodisponibilidade do elemento no solo.

\section{AGRADECIMENTOS}

Ao pesquisador Dr. Carlos Alberto da Silva Ledo, pela orientação nas análises estatísticas (Embrapa/ CNPMF) e a CAPES pela concessão de bolsa de estudos para o doutorado em Ciência do Solo.

\section{REFERÊNCIAS}

BOSSO, S. T.; ENZWEILER, J. Ensaios para determinar o (Bio)disponibilidade de $\mathrm{Pb}$ em solos contaminados. Química Nova, v. 31, n. 2, p. 394-400, 2008.

CHAO, T. T.; ZHOU, L. Extraction techniques for selective dissolution of amorphous irion oxides form soils and sediments. Soil Science Society American Journal, v. 47, n. 2, p. 225-232, 1983. 
CHEN, S. et al. Estimation of lead bioavailability in smeltercontaminated soils by single and sequential extraction procedure. Bulletin Environmental Contamination and Toxicology, v. 82, n. 1, p. 43-47, 2009.

CODEX ALIMENTARIUS - International Food Standards. Disponível em: <http://www.codexalimentarius.net/web/more info.jsp?id_sta=17>. Acesso em: 18 abr. 2010.

CONSELHO NACIONAL DO MEIO AMBIENTE. Resolução $n^{\circ}$ 420, de 28 de dezembro de 2009. Disponível em: <http:// www.mma.gov.br/port/conama/legiabre.cfm?codlegi=620>. Acesso em: 13 fev. 2010.

COSTA, C. N. et al. Fracionamento seqüencial de cádmio e chumbo em solos. Ciência Rural, v. 37, n. 5, p. 1323-1328, 2007.

EMPRESA BRASILEIRA DE PESQUISA AGROPECUÁRIA. Manual de análises químicas de solos, plantas e fertilizantes. Brasília: Embrapa Comunicação para Transferência de Tecnologia, 1999. $370 \mathrm{p}$.

EMPRESA BRASILEIRA DE PESQUISA AGROPECUÁRIA. Serviço Nacional de Levantamento e Conservação de Solo. Manual de métodos de análise de solo. 2.ed. Rio de Janeiro, 1997. 212 p.

GOPAL, R.; RIZVI, A, H. Excess lead alters growth, metabolism and translocation of certain nutrients in radish. Chemosphore, v. 70, n. 9 , p. $1539-1544,2008$.

GUEVARA-RIBA, A. et al. Assessment of metal mobility in dredged harbour sediments from Barcelona (Spain). Science Total Environmental, v. 321, n. 1/3, p. 241-255, 2004.

GUPTA, A. K.; SINHA S. Chemical fractionation and heavy metal accumulation in the plant of Sesamum indicum (L.) var. T55 grown on soil amended with tannery sludge: Selection of single extractants. Chemosphere, v. 64, n. 1, p. 161-173, 2006.

HONG, C. L. et al. Assessing lead thresholds for phytotoxicity and potential dietary toxicity in selected vegetable crops. Bulletin Environmental Contamination and Toxicology, v. 80, n. 4 , p. $356-361,2008$.

HUSSAIN, M.; LJAZ, S.; BIBI, M. Accumulation of nutrients and metal ions by two mung bean [Vigna radiate (L.) Wilczek] cultivars treated with copper and lead. Bulletin Environmental Contamination and Toxicology, v. 77, n. 4, p. 581-589, 2006.

ISHIKAWA, D. N. etal.Avaliaçãodo risco ambiental em sedimentos dos lagos do riacho Cambé, em Londrina, pela distribuição de metais. Química Nova, v. 32, n. 7, p. 1744-1749, 2009.

LANTMANN, A. F.; MEURER, E. J. Estudo de eficiências de extratores para avaliação de zinco disponível no solo para milho. Revista Brasileira de Ciência do Solo, v. 6, n. 2, p. 131-135, 1982.

LI, J. X. et al. Fractionation of lead in paddy soils and its bioavailability to rice plants. Geoderma, v. 141, n. 3/4, p.174-180, 2007.

LINDSAY, W. L.; NORWELL, W. A. Development of DTPA soil test for zinc, irion, manganese and copper. Soil Science Society of America Journal, v. 42, n. 3,p. 421-428, 1978.
LINHARES, L. A. et al. Adsorção de cádmio e chumbo em solos tropicais altamente intemperizados. Pesquisa Agropecuária Brasileira, v. 44, n. 3, p. 291-299, 2009.

LIU, D. et al. Uptake and accumulation and oxidative stress in garlic (Allium sativum L.) under lead phytotoxicity. Ecotoxicology, v. 18, n. 1, p. 134-143, 2009.

LU, A.; ZHANG, S.; SHAN, X-Q. Time effect on the fractionation of heavy metals in soils. Geoderma, v. 125, n. 3/4, p. 225-234, 2005.

MERWE, M. J. V. D. et al. Decreased mitochondrial activities of malate dehydrogenase and fumarase in tomato lead to altered root growth and architecture via diverse mechanisms. Plant Physiology, v. 149, n. 2, p. 653-669, 2009.

NASCIMENTO, C. W. A.; AMARASIRIWARDENA, D.; XING, B. Comparison of natural organic acids and synthetic chelates at enhancing phytoextraction of metals from a multi-metal contaminated soil. Environmental Pollution, v. 140, n. 1, p.114-123, 2006.

PAIVOKE, A. E. A. Soil lead alters phytase activity and mineral nutrient balance of Pisum sativum. Environmental Experimental Botany, v. 48, n. 1, p. 61-73, 2002.

SARMA, M.; HANDIQUE, G. K.; HANDIQUE, A. K. Toxic heavy metal stress in paddy: metal accumulation profile and development of a novel stress protein in seed. Indian Journal of Plant Physiology, v. 11, n. 3, p. 227-233, 2006.

SHARMA, P.; DUBEY, R. S. Lead toxicity in plants. Brazilian Journal Plant Physiology, v. 17, n. 1, p.35-52, 2005.

SAS Institute INC. SAS/STAT User's Guide. Versão 8.0. Cary: SAS Institute, Inc., 2000. v. I, II and v. III.

SHUMAN, L. M. Fractionation method for soil microelements. Soil Science, v. 140, n. 1, p. 11-22, 1985.

SILVA, M. L. S.; VITTI, G. C. Fracionamento de metais pesados em solo contaminado antes e após cultivo de arroz. Química Nova, v. 31, n. 6, p.1385-1391, 2008.

SINHA, P. et al. Alteration in uptake and translocation of essential nutrients in cabbage by excess lead, Chemosphere, v. 65 , n. 4 , p. $651-656,2006$.

TEKLIC, T. et al. Antioxidative responses in radish (raphanus sativus 1.) plants stressed by copper and lead in nutrient solution and soil. Acta Biológica Cracoviencia, v. 50, n. 2, p. 79-86, 2008.

TORRI, S.; LAVADO, R. Plant absorption of trace elements in sludge amended soils and correlation with soil chemical speciation. Journal Hazardours Materials, v. 166, n. 2/3, p. $1459-1465,2009$.

UNITED STATES ENVIRONMENTAL PROTECTION AGENCY. Method 3050 B. 1998. Disponível em: <http:// www. epa.gov/SW-846/pdfs/ 3050b.pdf>. Acesso em: 15 jan. 2010.

VERMA, S.;DUBEY, R. S.Lead toxicity induces lipid peroxidation and alters the activitieof antioxidant enzymes in growing rice plants. Plant Science, v. 164, n. 4, p. 645-655, 2003. 